\title{
1. X-RAY TECHNIQUES AND OBSERVATIONS ON DISTAL BENGAL FAN SEDIMENTS CORED DURING LEG 116
}

\author{
Dorrik A. V. Stow ${ }^{2,3}$ and Mark R. Townsend ${ }^{2}$
}

\begin{abstract}
A simple, nondestructive procedure for sampling cores for shipboard X-raying is outlined. It is suggested that the techniques be refined and more routinely employed on future Ocean Drilling Program legs. Subtle and hidden features of distal Bengal Fan turbidites and bioturbidites revealed by X-raying include: the nature of bed contacts, lamination in muds, extensive bioturbation that does not destroy lamination, grading and distinct contacts, and the distribution of authigenic iron sulfides. Coring disturbance caused by rotary coring operations is also readily observed on X-rays.
\end{abstract}

\section{INTRODUCTION}

Three closely spaced sites (Sites 717,718 , and 719) were drilled through the top kilometer of sediments on the distal Bengal Fan during Ocean Drilling Program (ODP) Leg 116 to the central Indian Ocean (Fig. 1). The section penetrated ranged in age from early Miocene to Holocene and was dominated by fine-grained turbidites. These sediments and the associated facies are described in detail elsewhere (see especially Stow et al., this volume).

Because certain aspects of the relatively uniform muddy sediments were not readily visible to the naked eye during shipboard description, representative intervals were X-rayed. The purpose of this paper is to briefly document the methods and results of this shipboard study. The technique used is a straightforward procedure most appropriately undertaken shortly after core description on board JOIDES Resolution. The additional information revealed by the X-raying is unique and we recommend that this technique be routinely employed on more ODP legs. We therefore describe the method in some detail.

\section{METHODS}

The sediment laboratory on JOIDES Resolution is equipped with a portable industrial X-ray unit. Most of the samples were placed in the lead-lined protective chamber and exposed for $7 \frac{1}{2} \mathrm{~min}$ at $36 \mathrm{kV}$ and $3 \mathrm{~A}$. These settings and exposure time were found from initial tests to be the most appropriate for $1 \mathrm{~cm}$ thick sediment slabs. Half-round core samples required significantly longer exposure times that ranged up to $15 \mathrm{~min}$.

The quality of the X-ray image is dependent in large part on the thickness of the sample being X-rayed. However, although thinner samples give a clearer image, it is not easy to take very thin slices of semiconsolidated sediments without seriously disturbing the sample. A compromise thickness of about 1.2 $\mathrm{cm}$ was therefore used for most samples. Extreme care at the sampling stage is essential to avoid undue disturbance that might mask any primary features.

The sampling technique that proved most successful is illustrated in Figure 2. A thin-sided, rectangular sample tray

\footnotetext{
${ }^{1}$ Cochran, J. R., Stow, D.A.V., et al., 1990. Proc. ODP, Sci. Results, 116: College Station, TX (Ocean Drilling Program).

2 Department of Geology, University of Nottingham, Nottingham NG7 2RD, U.K.

${ }^{3}$ Present address: Department of Geology, University of Southampton S 09 5 NH, U.K.
}

was inserted gently into the open side of a half-round core after the sediment surface had been carefully scraped flat and smooth. The full half-round section into which the sample tray had been inserted was then detached from the rest of the core section by vertical spatula cuts at each end and eased out onto a bench top. The sampled core section was blocked at one end and then a taut "cheese wire" was pulled along the upper edge of the sample tray. The remaining half-round section was gently eased off the sample in the tray and returned (properly orientated!) to the core liner. The exposed surface of the sample in the tray was cleaned before being X-rayed. Care must be taken to label each X-ray film with an appropriate sample number and way-up arrow. After X-raying, the slab can then be returned to the core liner intact, thus making this whole operation being completely nondestructive.

The following problems were encountered in using this technique and were not fully solved during this study:

1. For best results, both slab surfaces must be perfectly flat and smooth. This was not always readily achieved using the cheese wire and a spatula. Use of an osmotic knife proved less successful, although previous studies have used such a process with good effect (e.g., Coleman et al., 1986).

2. Neither very soft unconsolidated, nor hard consolidated sediments can be handled with the above technique. We did not manage to X-ray the former, whereas the latter were $\mathrm{X}$-rayed as full half-round core sections. Best results are obtained when half-round cores are mounted in a curved holder that is designed to compensate for the variable core thickness seen by the X-rays. Attempts to use a mud-filled plastic holder were not successful because the mud was insufficiently homogenized.

3. In some cases it would be simpler and more effective to X-ray a part of the $1.5-\mathrm{m}$ core section (either split or unsplit) without any sampling being required. This requires slight modification to the X-ray unit to allow pass-throughs of full-length core sections.

For further discussion of X-ray techniques on sediment cores the reader is referred to Bouma $(1964,1969)$.

\section{X-ray Prints}

About 50 separate core samples were X-rayed and most of these are present in Figures 3-9. They are printed as positive images so that the darker the color, the denser and more opaque the material to the passage of X-rays. The solid black rod- and thread-shaped bodies, for example, are highly 


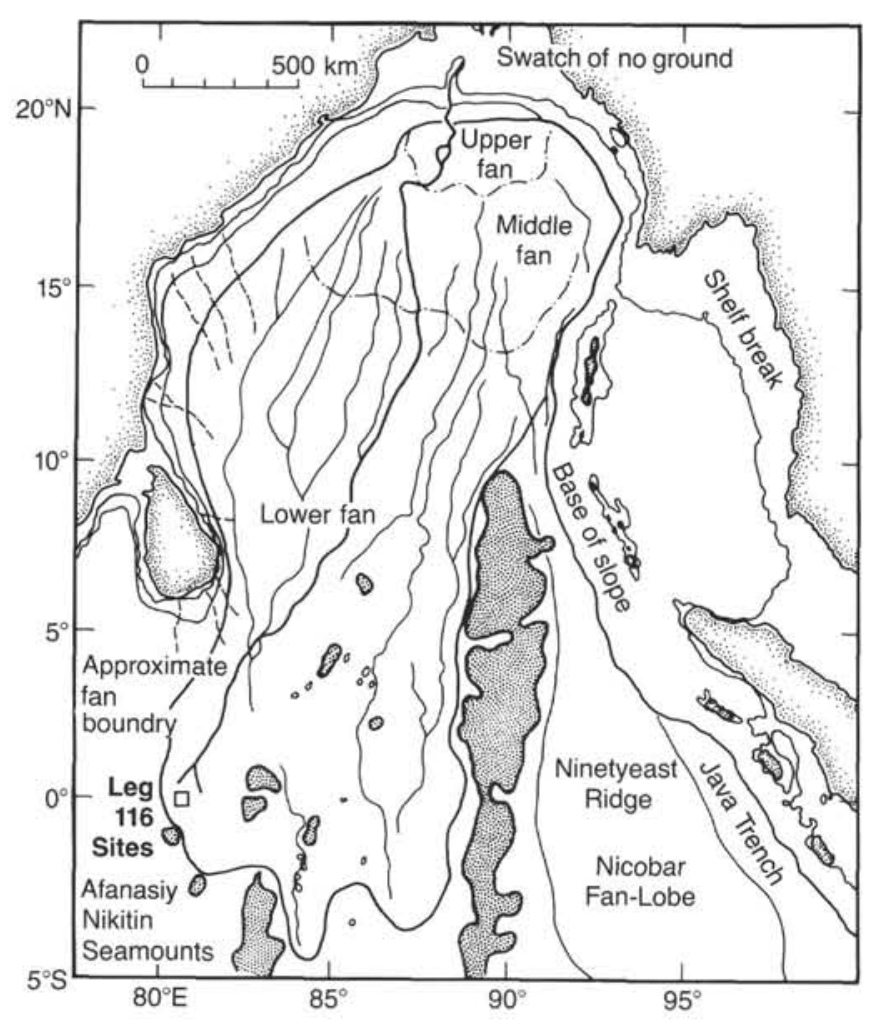

Figure 1. Location map of Leg 116 sites on the distal Bengal Fan, central Indian Ocean. Base map after Emmel and Curray (1984).

opaque authigenic iron sulfides, whereas blank white zones are open cracks and fractures.

Before describing the primary features observed on the $\mathrm{X}$-rays, we must first document those features that resulted from disturbance during either the coring operation or the sampling procedure.

\section{CORING AND SAMPLING DISTURBANCE}

Densely packed, silty and sandy sediments in the top $100-150 \mathrm{~m}$ of section at each of the three sites drilled, prevented the use of hydraulic piston coring below about 5 meters below seafloor (mbsf). Instead, rotary coring, with an extended core barrel beyond the bit, was used for the full penetration at each site. This led to considerably more disturbance of the sediment than we had expected, as is clearly demonstrated on X-ray images (Fig. 3). However, such coring disturbances were generally discontinuously distributed.

Extreme homogenization of the sediment has occurred in some instances (e.g., Fig. 3A), especially in the topmost sections of cores. The more cloudy, disturbed aspect observed on other X-rays (e.g., Fig. 3A) is probably the result of partial homogenization, whereas slight mobilization and injection of sediment is also evident in some cases (Fig. 3E).

Nearly all of the cored sections had a tendency to "break" into thin disks, typically between 1 and $3 \mathrm{~cm}$ thick, during rotary coring. Ground-up formation mud and clay were then forced between individual disks as coring proceeded and the disks themselves often suffered considerable rotation. Although this process is a well-known feature of rotary coring, it repeatedly results in lively debate among shipboard scientists as to its primary or secondary origin (e.g., Cremer and Stow 1986). The individual disks are known as "biscuits," and we here refer to the subhorizontal breaks separating biscuits as "biscuit-fractures." Well-developed, closely spaced biscuits are present in Figure 3B, more widely spaced ones in Figure 3E. They are less distinct
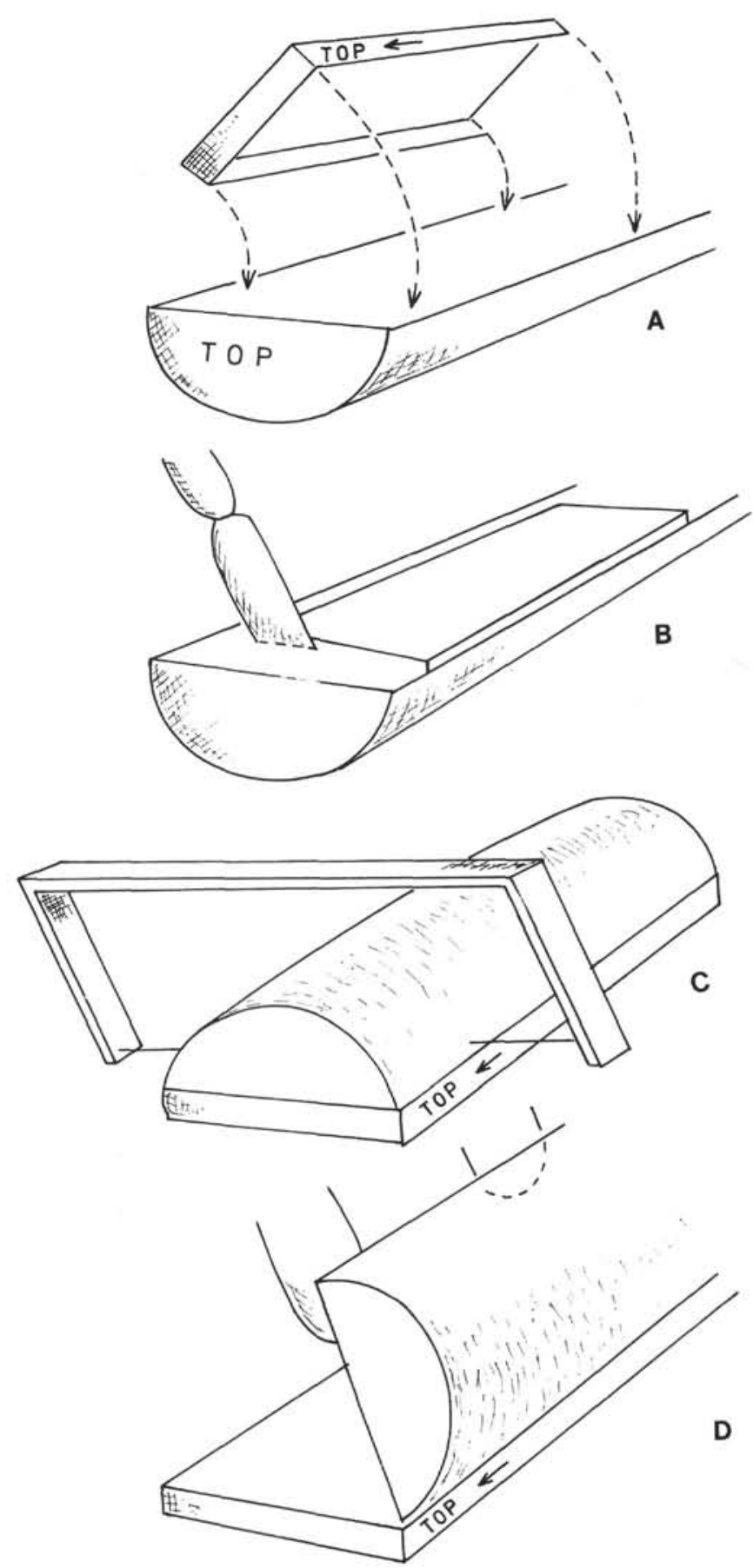

Figure 2. Schematic illustration of shipboard sampling technique for obtaining thin slabs of core for X-rays. A. Insertion of sample tray into cleaned, half-round core. B. Full cut to base of half-round and both ends of sample. C. Fine cut with cheese wire to separate slab from part round. D. Removal of rounded core portion from slab, using spatulas. See text for full description.

in Figure 3C, whereas in Figure 3D the biscuit-fractures are not continuous across the width of the core, but instead form an interlocking lenticular pattern.

All forms of biscuit disturbance were found to be very common in the Bengal Fan cores, although in many sections they are apparently absent or only very minor. We have not determined the causes for these differences, but assume that they relate in part to lithology, as well as to drilling factors such as constancy of weight on bit, ship heave, etc. Drilling 


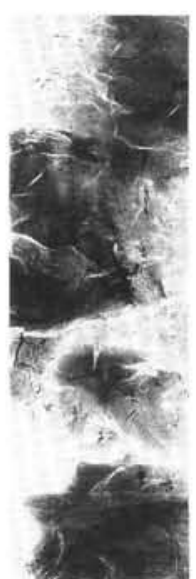

A

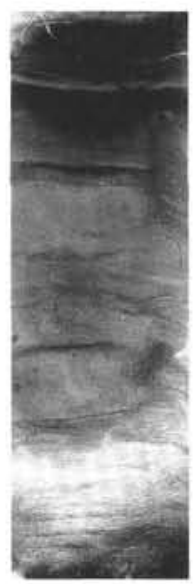

$\mathbf{E}$

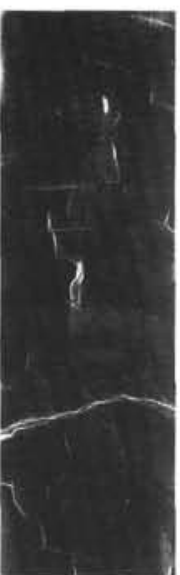

B

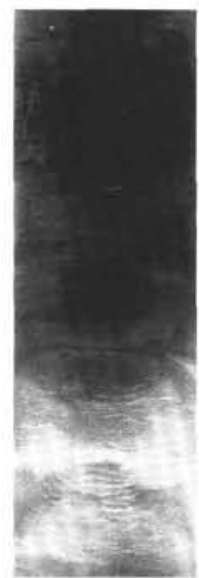

$\mathbf{F}$

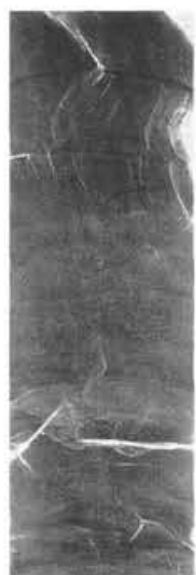

C

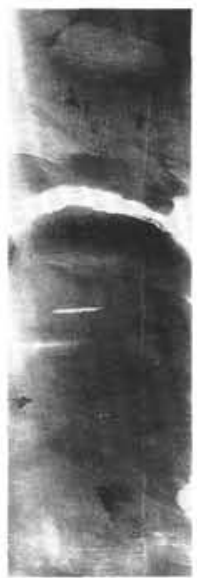

G

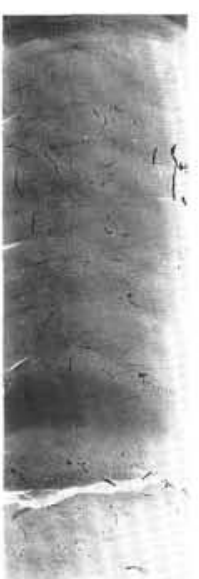

D

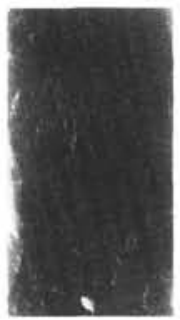

H

Figure 3. X-rays of Bengal Fan cores illustrating the range of features due to disturbance by the XCB-rotary coring operation, and by sampling procedures. $\mathrm{BF}=$ biscuit-fracture between individual biscuits (see text for discussion). $\mathbf{A}$. Sample 116-717C-29X-1, 10-27 cm. Intense coring disturbance of pelagite and top part of dark-gray turbidite. Note almost random open frature pattern (white) showing considerable churning of soft sediment. B. Sample 116-717C$24 \mathrm{X}-2$, 96-113 cm. Mid part of biogenic turbidite showing thin curved subhorizontal biscuit-fractures (dark) at $1-$ to $2-\mathrm{cm}$ spacing. The coring process has fractured the cored material into these slabs (biscuits), which have suffered various rotations. Note truncated, subvertical authigenic iron-sulfide threads (black), and open fractures (white). C. Sample 116-719A-17X-3, 61-88 cm. Lower part of biogenic turbidite showing less pronouced biscuit-fractures (dark) than in B. Note the effects on authigenic iron-sulfide threads (black) and on open fractures (white) of rotation of individual biscuits near top of X-ray. D. Sample 116-719A-22X-5, 98-115 cm. Top part of dark-gray turbidite showing discontinuous lenticular fracture pattern (dark). These appear similar to the biscuit-fractures in B but are less well developed and generally not continuous across the core width. Instead they form interlocking lenses. E. Sample 116-719A-41X-6, 35-52 cm. Part of light-gray silt-mud turbidite showing coring disturbance (biscuit-fractures, dark) and slight sediment injection (right side). Open fracture pattern (white) toward base is due to sampling process. F. Sample 116-718C-46X-2, 72-89 cm. Part of silt mud turbidite showing generally disturbed fabric (coring), together with marked fracture pattern in lower part (white) due to disturbance during sampling. G. Sample 116-718C-41X-5, 104-123 cm. Part of thick light-gray bioturbidite (?) showing intense coring disturbance and bioturbation. Note subvertical fractures, subhorizontal biscuit-fractures, and general homogenization. White line toward right also due to sampling. H. Sample 116-717C-8X-2, 45-55 cm. Part of thin dark-gray turbidite showing vertical fabric, possibly due to dewatering or fracturing during coring. 
biscuits with "chocolate" mud fillings were particularly striking in thin, clean silt beds, but the unconsolidated nature of the silts made it impossible to X-ray these sections.

Many of the X-rays show open fractures, ranging from the micro or hairline scale to larger open gaps in the core sections. In most cases, these can probably be related to the post-coring procedures including core-splitting and sampling for X-raying. The distinctive, crenulated, crescentic fracture patterns observed at the bottom of core sections in Figures $3 \mathrm{E}$ and $3 \mathrm{~F}$, for example, are apparently caused by slight flexure or extension of the slab during sampling.

The subvertical, short, wispy pattern evident in Figure $3 \mathrm{H}$ is less common and less clearly understood. It is either due to some lateral stress effect during sampling or, perhaps, is due to natural dewatering of the mud during compaction.

\section{DISTAL FAN FACIES}

Seven different facies have been recognized in sediments from the three sites drilled on the distal fan (Cochran, Stow et al., 1989; Stow et al., this volume). The general characteristics of these facies are outlined below and some of these distinctive features in X-rays are illustrated in Figures 4 through 9.

\section{Facies 1}

The silt and silt-mud turbidites (Fig. 4) are sharp-based, upward fining beds of dark-gray silt, or less commonly sandy silt, that grade upward through silty clay to clay. Internally these beds may be massive, or, rarely, show a faint horizontal lamination in the basal few centimeters. The beds of this facies range from 7 to $140 \mathrm{~cm}$ thick, averaging $40 \mathrm{~cm}$. Bioturbation and calcareous microfossils are rare.

\section{Facies 2}

The light-gray, organic-poor, mud turbidites (Fig. 5) are sharp-based, thickly to very thickly $(30-220 \mathrm{~cm})$ bedded, light-gray to gray, silty clays that grade upward into clay. Silt typically comprises only $10 \%$ of the sediment and is concentrated in the lowermost third of each bed. The bases of beds are often marked by clean silt laminae, one grain diameter to several millimeters thick. The silt fraction consists mainly of quartz with mica (less than 10\%) and feldspar (traces). Plant debris make up less than $1 \%$. Bioturbation and calcareous microfossils are largely absent.

\section{Facies 3}

The dark-gray, organic-rich, mud tubidites (Fig. 6) are characterized by large amounts $(2 \%-15 \%$, avg. $5 \%)$ of plant debris and typically occur as dark-gray to black, sharp-based, upward fining beds that are $50-100 \mathrm{~cm}$ thick (avg. $80 \mathrm{~cm}$ ). The beds generally commence with silty clay (less than $80 \%$ silt) and pass upward into clay. Typically the basal centimeters exhibit horizontal lamination that passes upward into a faint, wispy lamination and finally into a massive interval. Pyrite (after wood, burrows, and as concretions) is ubiquitous. The tops of the beds are commonly bioturbated.

\section{Facies 4}

This facies consists of biogenic mud turbidites (Fig. 7), sharp-based, upward fining, olive-gray calcareous silty clays (with a silt content less than $10 \%$ ), and clay. Beds of this facies range in thickness from 10 to $290 \mathrm{~cm}$ (avg. $50 \mathrm{~cm}$ ). A thin (less than $3 \mathrm{~cm}$ ) basal silt layer may occur. Rarely, a faint horizontal lamination is present, but most commonly the beds appear massive. Calcareous microfossils are ubiquitous and make up as much as $20 \%$ of the sediment. In addition, unidentified calcareous silt and clay-sized material accounts for $20 \%$ to
$30 \%$ of the sediment. The tops of the beds are commonly bioturbated.

\section{Facies 5}

This facies consists of beds of pelagic clays (Figs. 8A-8C) $5-25 \mathrm{~cm}$ thick, with graduated bases and color ranging from mottled red-green to gray. Bioturbation and ferromaganiferous (?) chemical fronts characterize the facies. Calcareous microfossils are rare to absent: those that remain show evidence of extreme dissolution.

\section{Facies 6}

This facies consists of light to dark-gray bioturbated, pelagic calcareous clays (Fig. 8D) with approximately $5 \%$ silt and abundant nannofossils (to $50 \%$ ) and foraminifers (up to $5 \%$ ). Bioturbation is common and intense.

\section{Facies 7}

Bioturbated muds (Fig. 9) occur in beds $10-100 \mathrm{~cm}$ thick of dark- to light-gray silty clay and clay with indistinct bed boundaries in Facies 7. The beds are typically thoroughly bioturbated throughout and yet retain aspects typical of mud turbidites such as lamination and grading. Calcareous microfossils are rare to absent. These have been called "hemiturbidites" by Stow and Wetzel (this volume) and are discussed in detail in their paper.

\section{SEDIMENT FEATURES FROM X-RAYS Bed Contacts}

The basal contacts of turbidite beds are invariably sharp. Mud turbidites mostly have sharp, flat, nonerosive bases (e.g., Figs. 6B, 6C) or micro-erosive bases (e.g., Figs. 5D, 5H), whereas both silt-mud turbidites and the coarser grained biogenic turbidites typically have markedly irregular erosive bases (e.g., Figs 6F, 7A). The top of each turbidite bed is then either sharp, if overlain by the succeeding turbidite, or completely gradational, if overlain by a pelagic clay or bioturbated mud (e.g., Figs. 6A-6E, 6D, 6H). Erosive surfaces have also been noted internally in turbidite beds (Fig. 4D).

In many cases, the bases of the bioturbated beds appear visually sharp and distinct in the cores, but in X-rays these contacts appear slightly more diffuse and thoroughly bioturbated (e.g., Figs 9A, 9B, 9C). Similarly, the apparently sharp contacts of some pelagic calcareous clays are seen to be more diffuse and bioturbated on X-rays (Fig. 8D). The sharp appearance may be accentuated by a marked color change indicating a chemical front.

\section{Dynamic Structures}

When examining the X-rays for evidence of dynamic structures, it is important to distinguish between biscuitfractures and lamination.

The silts of the silt-mud turbidites (Facies 1) and those at the base of thick, dark-gray turbidites (Facies 3) show a range of structures that are typically associated with deposition from turbidity currents, including: parallel lamination, cross-lamination, lentincular bedding, and low-angle cross-lamination (e.g., Figs. 4A, 5A, 6E, 6F, 6H). Similar structures are present in the coarser grained biogenic turbidites (e.g., Fig. 7A). Perhaps more interesting is the common occurrence of parallel lamination in mud turbidites (e.g., Figs. 5, 5E, 6E, 6H) and even, in some cases, cross-lamination (e.g., Fig. 5G). However, many of the mud turbidites appear completely structureless. It is also noteworthy that the thorough bioturbation of certain muds (Facies 7) and of some thin turbidites has not fully destroyed the original lamination (e.g., Figs. 6D, 9C, 9D, 9E, and 9H). 


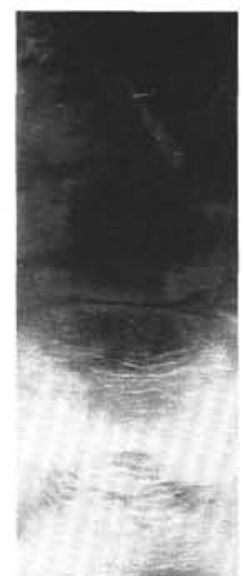

A

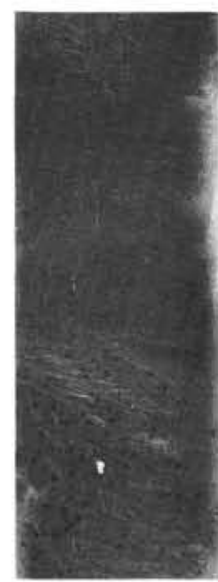

B

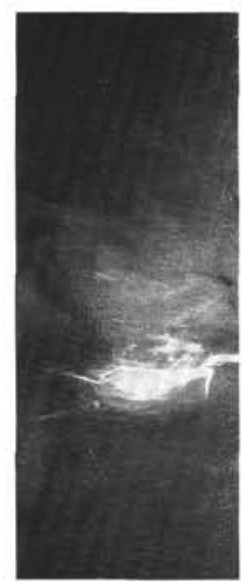

c

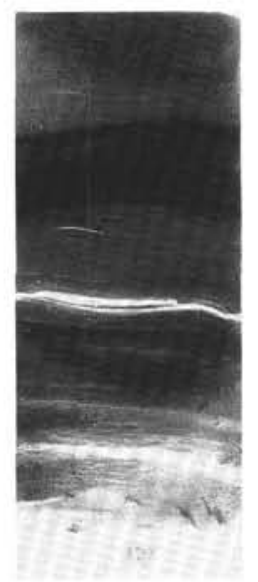

D

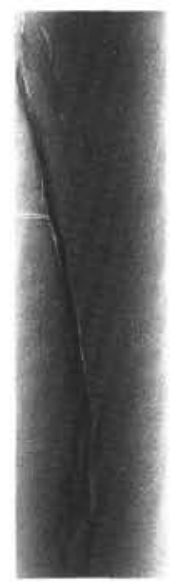

E

Figure 4. X-rays of Bengal Fan illustrating some of the features observed in light-gray colored silt-to-mud turbidites (Facies 1). A. Sample 116-718C-46X-2, 74-89 cm. Part of medium thick $(21 \mathrm{~cm})$ silt mud turbidite. Note generally structureless/disturbed fabric, grading from siltier (lighter colored) at base to muddier upward; sampling fracture disturbance in lower part. B. Sample 116-717C-14X-2, 44-57 $\mathrm{cm}$. Lower part of thick silt-mud turbidite. Note generally homogeneous fabric with minute vertical and horizontal fractures; note also speckled dark mottles-possibly being authigenic iron-sulfide framboids. C. Sample 116-718C-46X-1, $72-85 \mathrm{~cm}$. Mid part of thick $(35 \mathrm{~cm})$ silt-mud turbidite. Note generally structureless fabric. D. Sample 116-718C-46X-1, 126-139 cm, near base of medium thick $(30 \mathrm{~cm})$ silt mud turbidite with clean silt laminae. Note lamination, grading upward to mud (pale), internal surface toward top. E. Sample 116-717C-87X-CC, $23-38 \mathrm{~cm}$. Carbonate-cemented and fractured silty-sand turbidite. Note generally structureless fabric, with possible development of weak lamination toward top.

\section{Grading}

The very subtle grading apparent in some of the thick mud turbidites and bioturbated muds (despite thorough bioturbation), is evident on X-Rays (e.g., Figs. 6A-6E, 6B, 6D, 8C, 9C, 9D, 9E). For the dark-gray mud turbidites and also for some light-gray turbidites, the complete color grading on $\mathrm{X}$-rays is from black at the base to very light gray, then progressively darker gray, and finally to a light gray color. This graduation is, of course, a reflection of changes in bulk density, which is controlled by sediment grain size, packing, and composition. The black base is iron sulfide-rich quartz silt. The upward grading from light to dark is the reverse of that expected from an upward-decreasing grain size and is most probably related to increasing organic carbon and related finely disseminated authigenic iron sulfides within the turbidite. The lighter colored pelagite is then both finer grained and poorer in organic/iron-sulfide content.

\section{Bioturbation}

$\mathrm{X}$-ray images are particularly valuable for detailed study of bioturbation in sediments. In the sections examined, a range of intensity of bioturbation is evident, from completely unbioturbated to very thoroughly burrowed. Both microbioturbation and distinctive micro-burrows are present, although we leave discussion of the generic and specific ichnofossils to a separate paper (Wetzel and Wijayanada, this volume).

The extent of bioturbation typically present in these distal fan turbidites is particularly significant (e.g., Figs. 6D, 7B, 9C, 9D). The depth of penetration of burrowing from the tops of turbidites and, especially in the case of bioturbated muds, the complete bioturbation across bed contacts, is distinctive. These relationships probably reflect extremely slow deposition from the final stages of turbidity currents that allows bioturbation to continue throughout (see Stow and Wetzel, this volume).

\section{Diagenesis}

Most of the early diagenetic changes that have taken place in these distal fan sediments are very subtle and not readily observed in X-rays. However, the occurrence of authigenic iron sulfides is very evident because they are quite opaque to $\mathrm{X}$-rays and therefore appear black on the positive prints. Iron sulfides are most often associated with the dark-gray (organic carbon-rich) turbidites (Fig. 6) and to a lesser extent, with thin pelagic horizons (Fig. 8D). They are much less abundant in the other facies.

Fine disseminated sulfides occur in the basal silty portions as well as in the mid to upper muddy parts of the dark gray turbidites. Thin hairlike mycelia, thicker threads $(<0.5 \mathrm{~mm})$ and fairly stout rods $(<1.5 \mathrm{~mm})$ of iron sulfide are common. The size of authigenic iron-sulfide bodies typically increases upward through a turbidite bed. A subvertical orientation of threads and rods appears most common, although horizontal and inclined examples also occur. This distribution and morphology are presumably related to the supply of iron and sulfur within the sediment, and to the pathways of pore fluids during early compaction. Larger, more irregular-shaped masses of iron sulfide tend to occur in the pelagic horizons.

Distinctive, pale purple-colored, chemical fronts are common in the cores toward the tops of turbidites and within pelagic intervals. These are barely visible on X-rays (Fig. 8A).

\section{DISCUSSION}

The sediments recovered from the three Bengal Fan sites (717, 718 and 719 ) during Leg 116 are quite distinctive in their characteristics, which are most probably related to their extre me distal location. Many sedimentary features are either best studied or are only observable on X-rays, including: the precise nature of bed contacts, evidence of lamination and cross-lamination in mud turbidites, the extent and degree of bioturbation, and the morphology and distribution of authi- 


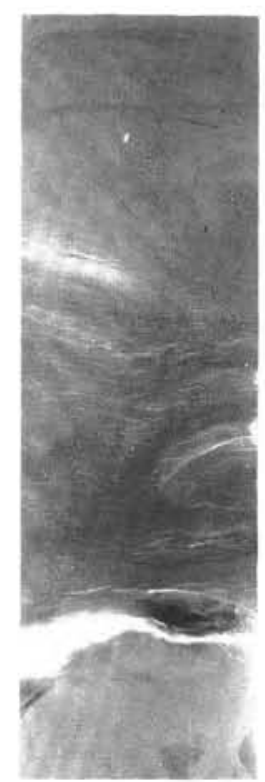

A

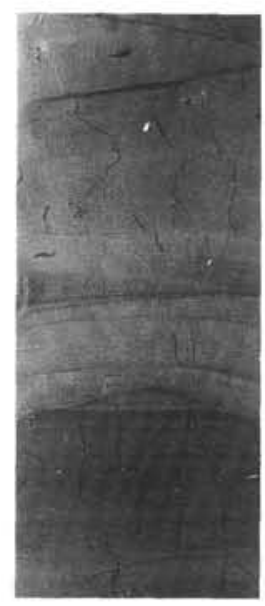

$\mathbf{E}$

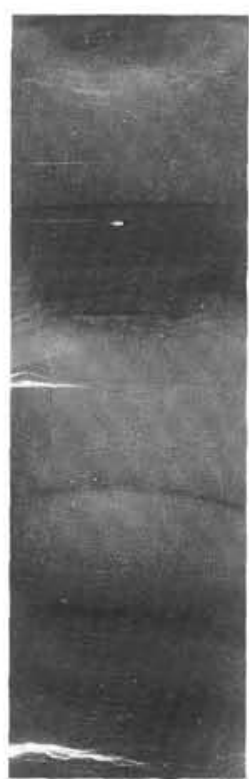

B

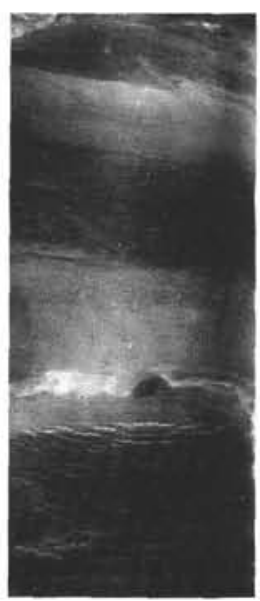

$\mathbf{F}$

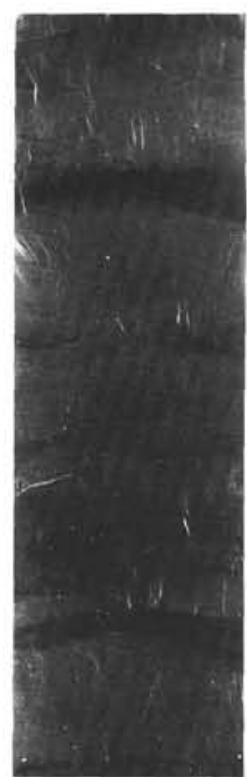

C

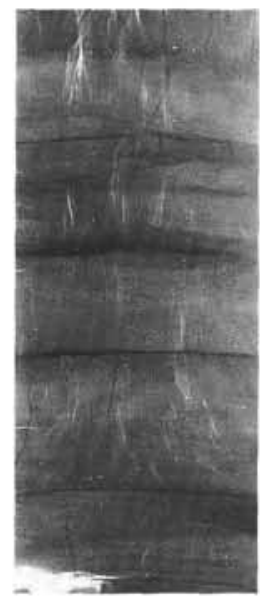

G

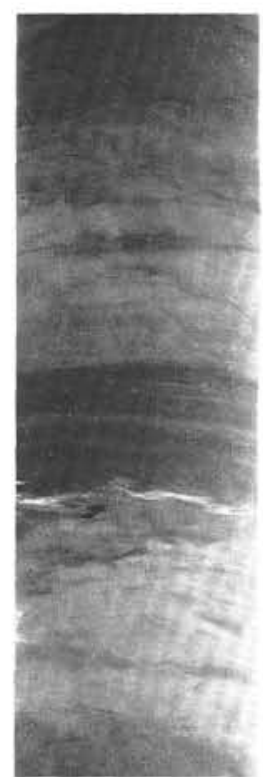

D

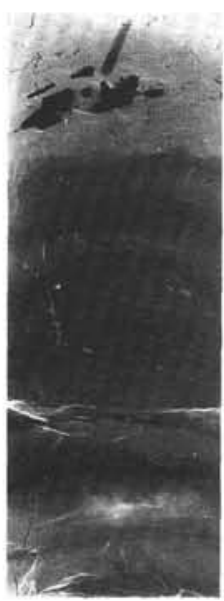

H

Figure 5. X-rays of Bengal Fan cores illustrating some of the features observed in light-gray colored mud turbidites (Facies 2). A. Sample 116-718C-16X-1,93-110 cm. Basal part of medium-thick light-gray turbidite with isolated silt lens at base. It lies sharply over bioturbated pelagic clay that grades downward into top of underlying light-gray turbidite. B. Sample 116-718C-37X-1, 105-122 cm. Thin light-gray turbidites with thin silt bases. Note biscuitfractures due to coring make grading more difficult to observe clearly. C. Sample 116-717C-26X-6, 47-64 cm. Mid part of thick $(105 \mathrm{~cm})$ light-gray turbidite-hemiturbidite, whereas the underlying turbidite is shown in G, below. Note thorough bioturbation between biscuit fractures. D. Sample 116-718C-15X-2, 108-125 cm. Thin light-gray turbidite overlying bioturbated pelagic clay and grading upward into bioturbated turbidite, then pelagic clay. E. Sample 116-718C-13X-2, 47-60 cm. Thin light-gray turbidite grading upward into bioturbated pelagic or hemiturbidite. Note grading, lamination, and bioturbation; dark horizontal lines are biscuit-fractures that commonly break authigenic iron-sulfide mycelia. F. Sample 116-718C-3X-2, 78-94 cm. Two thin light-gray turbidites. Note sharp base, grading from silty (dark) to muddy (light), lamination and bioturbation. G. Sample 116-717C-26X-6, $118-131 \mathrm{~cm}$. Basal part of thick light-gray turbidite with thin $(5 \mathrm{~mm})$ clean silt at base. Note lamination and cross-lamination in silty-mud and subvertical authigenic iron-sulfide mycelia between biscuit-fractures. $\mathbf{H}$. Sample 116-717C-21X-3,116-129 cm. Base of dark-gray turbidite with authigenic iron sulfides over top part of light-gray turbidite. Note sharp contact and biscuit-fractures in lower unit. 


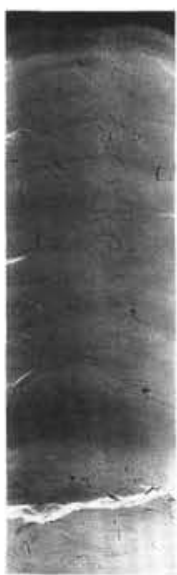

A

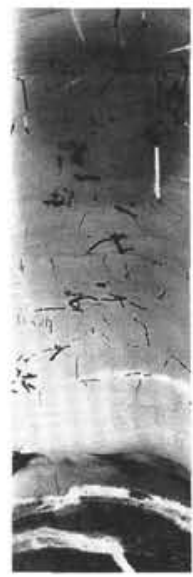

E
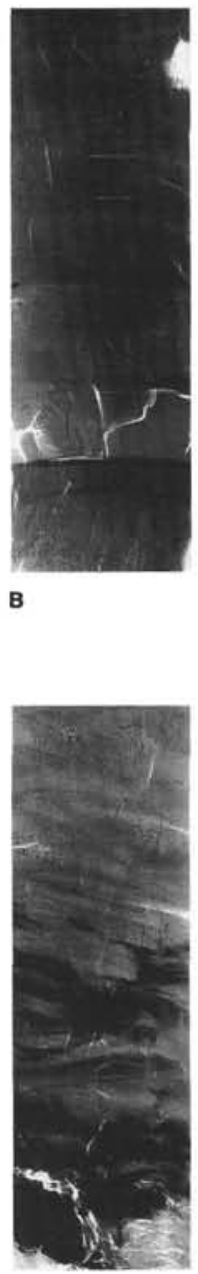

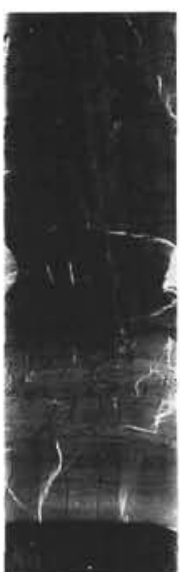

C

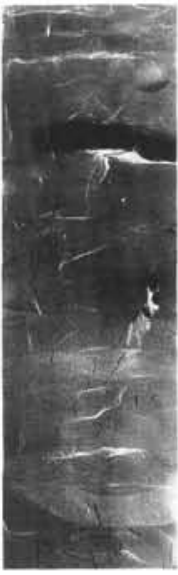

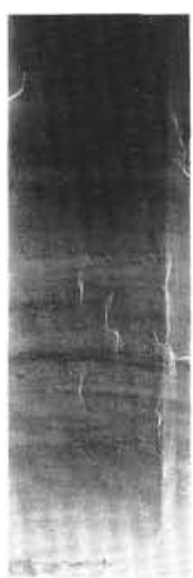

D

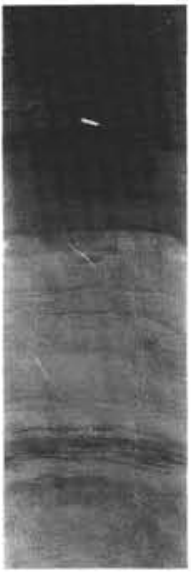

Figure 6. X-rays of Bengal Fan cores illustrating some of the features observed in dark-gray mud turbidites (Facies 3). A. Sample 116-719A-22X-5, 98-115 cm. Top part of thick $(36 \mathrm{~cm})$ dark-gray turbidite overlain by silty base of subsequent turbidite (black). Note structureless fabric with probable coring disturbance and authigenic iron sulfide. This section overlies the X-ray in E, below. B. Sample 116-717C-33X-6, 33-50 cm. Basal part of thin-medium dark-gray turbidite overlying top part of light-gray turbidite. Note sharp contact (now accentuated by biscuit-fracture), indistinctly laminated-homogeneous fabric between biscuit-fractures, and only slight development of authigenic iron sulfides. C. Sample 116-717C-30X-4, 23-40 cm. Basal part of medium-thick dark-gray turbidite overlying pelagic clay. Note sharp base grading, lamination between biscuitfractures, and extensive authigenic iron-sulfide development. D. Sample 116-719A$16 \mathrm{X}-5,125-142 \mathrm{~cm}$. Medium thick $(24 \mathrm{~cm})$, dark-gray turbidite. Note grading, lamination, and bioturbation throughout; laminae decrease upward, burrowing decreases downward, authigenic iron sulfide is more abundant upward. E. Sample 116-719-22X-5, $119-136 \mathrm{~cm}$. Bottom of thick $(36 \mathrm{~cm})$ dark-gray turbidite underlying the X-ray A, above. Note silty base (black) with indistinct lamination, overlain by structureless mud with authigenic iron sulfides. F. Sample 116-719A-31X-3, 30-47 cm. Basal part of thick (40 $\mathrm{cm}$ ) dark-gray turbidite grading up into a hemiturbidite. Note sharp irregular base, clean silt laminae (black) overlain by laminated-to-structureless mud, bioturbated and graded throughout; disturbance is due mostly to coring. G. Sample $116-717 \mathrm{C}-24 \mathrm{X}-3,17-34 \mathrm{~cm}$, near top of meter-thick dark-gray turbidite. Note authigenic iron-sulfide mycelia threads, homogeneous/mottled fabric between biscuit deformation. Dark partial layer near top is part of large curved burrow trace. H. Sample 116-719A-17X-5, 113-130 cm. Part of medium thick $(21 \mathrm{~cm})$ dark-gray turbidite overlying pelagite and grading upward to lighter gray mud (dark on X-ray) and then to pelagite. Note sharp base, thin zone of clean silt laminae, then structureless fabric to bioturbated mud. 


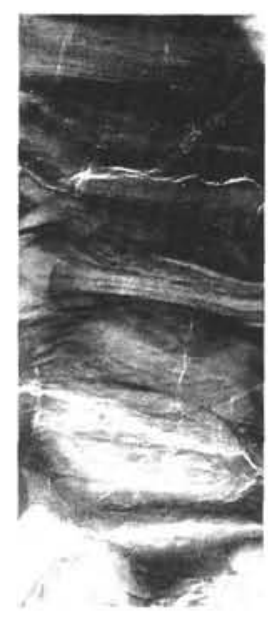

A

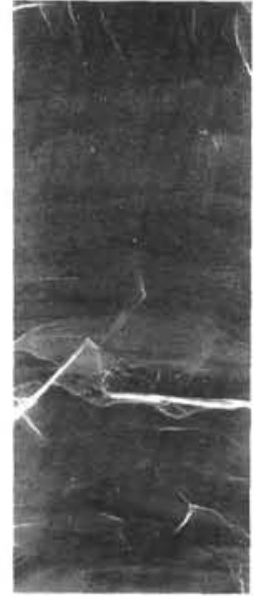

B

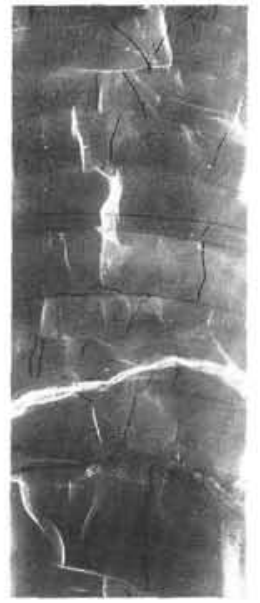

C

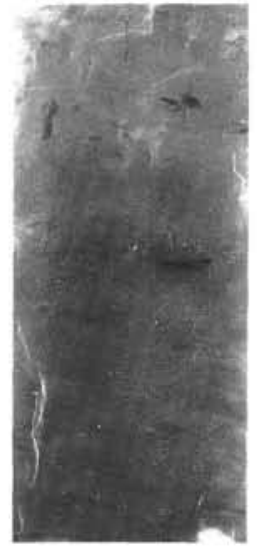

D

Figure 7. X-rays of Bengal Fan cores illustrating some of the features observed in greenish colored biogenic turbidites (Facies 4). A. Sample 116-719A-16X-4, 123-139 cm. Base of thick $(110 \mathrm{~cm})$ biogenic turbidite. Note sharp erosive base, coarse-grained structureless lower division passing upward to laminated and cross-laminated divisions. B. Sample 116-719A-17X-3, 61-88 cm. Base of medium thick biogenic turbidite overlying dark-gray turbidite. Note sharp basal contact, finer grained size than A, lamination grading and bioturbation throughout; biscuit-fractures are particularly evident near top. C. Sample 116-717C-14X-2, 95-115 cm. Mid part of biogenic turbidite. Note faint lamination between distinct biscuit-fractures. D. Sample 116-719A-16X-4, 12-23 cm. Uppermost part of thick $(110 \mathrm{~cm})$ biogenic turbidite shown in A. Note structureless, bioturbated fabric.

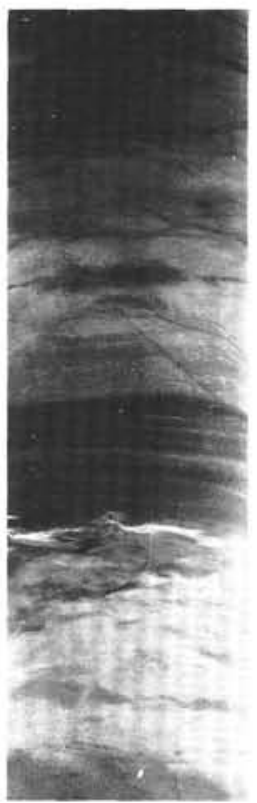

A

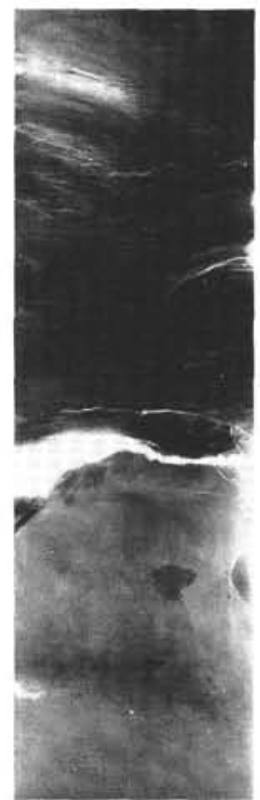

B

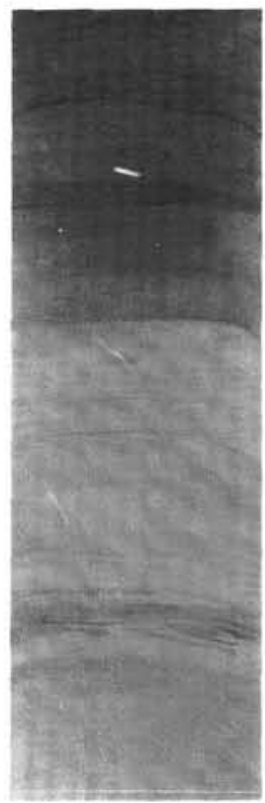

C

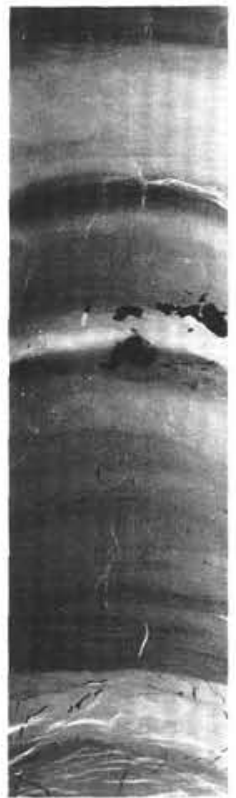

D

Figure 8. X-rays of Bengal Fan cores illustrating some of the features observed in pelagic clays (Facies 5) and calcareous muds/muddy oozes (Facies 6). A. Sample 116-718C-15X-2, 108-125 cm. Thin light-gray turbidite sharply overlying bioturbated pelagic clay and grading upward into bioturbated turbidite, then pelagic clay. Note microfractures and biscuit-fractures are due to coring process; chemical front within upper zone is marked by slight density change from darker to lighter color on X-ray. B. Sample 116-718C-16X-1,93-110 cm. Lower unit shows bioturbated pelagic clay grading downward into top of light-gray turbidite. C. Sample 116-719A-17X-5, 110-127 $\mathrm{cm}$. Pelagic clay overlying dark-gray turbidite. Note bioturbated fabric. D. Sample $116-717 \mathrm{C}-22 \mathrm{X}-5,56-73 \mathrm{~cm}$. Series of thin dark-gray turbidites, separated by calcareous pelagites. Note authigenic iron-sulfide concentration adjacent to pelagic horizon and the grading and lamination. 


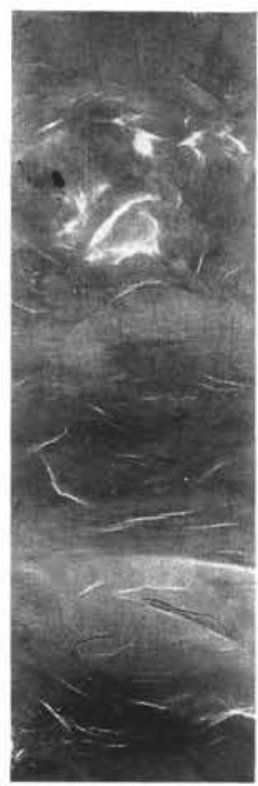

A

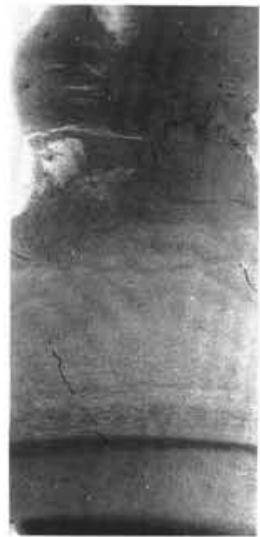

E

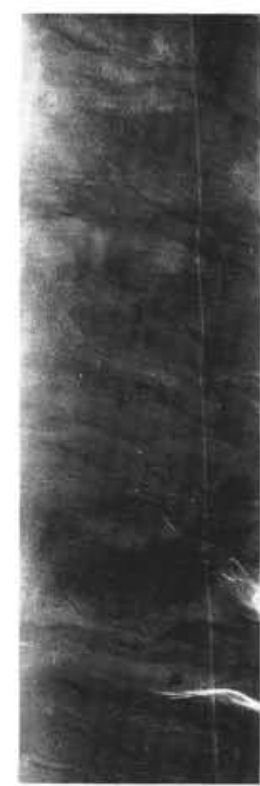

B

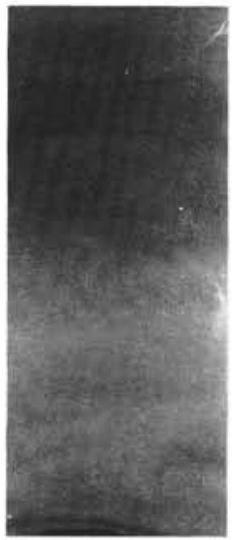

$\mathbf{F}$

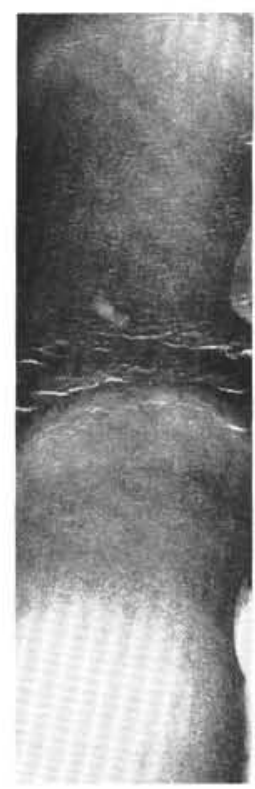

C

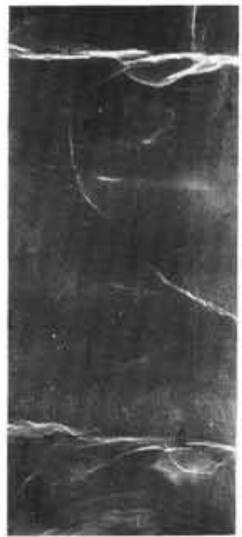

G

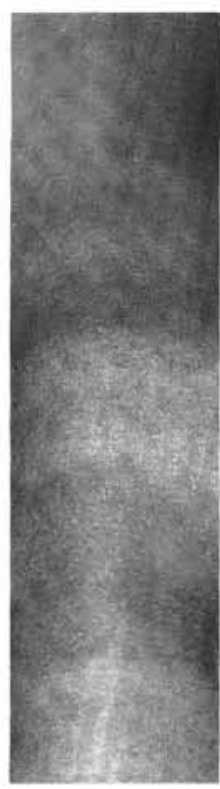

D

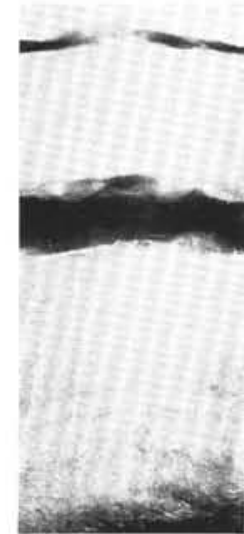

H

Figure 9. X-rays of Bengal Fan cores illustrating some of the features observed in bioturbated muds (Facies 7). (Note: these sediments are termed "hemiturbidites" by Stow and Wetzel, this volume). A. Sample 116-719A-29X-1, $47-64 \mathrm{~cm}$. Basal part of thick $(60 \mathrm{~cm})$ light-gray turbidite/bioturbated mud. Note bioturbation throughout, disturbed silt base, and slight gradation. B. Sample 116-718C-41X-5, 140-147 cm. Part of thick light-gray bioturbated mud showing coring disturbance and sampling disturbance as well as bioturbation. C. Sample 116-718C-1H-6, 123-140 $\mathrm{cm}$. Two thin, light-gray bioturbated mud beds. Note bioturbation and grading throughout. Bed contact is also bioturbated. D. Sample 116-718C-1H-5, 123-150 cm, near base of light-gray, thoroughly bioturbated, thick bedded $(3 \mathrm{~m})$ mud. Note intense microburrowing throughout. E. Sample $116-718 \mathrm{C}-13 \mathrm{X}-2,60-72 \mathrm{~cm}$. Part of thin bioturbated mud with sharp base over top of light-gray turbidite. F. Sample $116-718 \mathrm{C}-16 \mathrm{X}-1,112-124 \mathrm{~cm}$. Part of thin bioturbated mud $(15 \mathrm{~cm}$ thick) or thoroughly bioturbated dark-gray turbidite. Note bioturbation from sharp base upward (Phycosiphon) as well as grading. G. Sample 116-717C-24X-2, 138-150 cm. Part of bioturbated dark-gray mud. Note bioturbated/structureless fabric. H. Sample 116-718C-3X-2, 110-122 cm. Lower part of light-gray turbidite/bioturbated mud. Note bioturbation throughout.

genic iron sulfides. Interpretation of some of these features is treated elsewhere in the relevant sedimentology papers of this volume, whereas other aspects remain to be studied. The $\mathrm{X}$-rays also serve to emphasize the degree and nonuniformity of coring disturbance suffered during rotary coring operations. Our inability to easily X-ray unconsolidated silts and sands and, more importantly, our inability to satisfactorily recover such sediments in the first place, needs to be overcome in the future.

\section{ACKNOWLEDGMENTS}

Secretarial and technical support to DAVS at the Universities of Nottingham and Southampton is gratefully acknowledged. All the sedimentologists and other participants on 
board JOIDES Resolution (Leg 116) are also thanked for their patience and assistance with shipboard operations.

\section{REFERENCES}

Bouma, A. H., 1964. Notes on X-ray interpretation of marine sediments. Mar. Geol., 2:278-309.

1969. Methods for the Study of Sedimentary Structures: New York (Wiley-Interscience).

Cochran, J. R., Stow, D.A.V., et al., 1989. Proc. ODP, Init. Repts., 116: College Station, TX (Ocean Drilling Program).

Coleman, J. M., Bouma, A. H., Roberts, H. H., and Thayer, P., 1986. Stratification in Mississippi Fan cores revealed by X-ray radiography. In Bouma, A. H., Coleman J. M., Meyer, A. W., et al., Init. Repts. DSDP, 96: Washington (U.S. Govt. Printing Office), 505-517.

Cremer, M., and Stow, D.A.V., 1986. Sedimentary structures of fine-grained sediments from the Mississippi Fan: thin-section analysis. In Bouma, A. H., Coleman J. M., Meyer, A. W., et al., Init. Repts. DSDP, 96: Washington (U.S. Govt. Printing Office), 519-532.

Emmel, F. J., and Curray, J., 1984. The Bengal Submarine Fan, northeastern Indian Ocean. Geo-Mar. Lett., 3:119-124.

Date of initial receipt: 7 July 1989

Date of acceptance: 5 February 1990

Ms 116B-111 